\title{
$\alpha$-Pinene secondary organic aerosol at low temperature: chemical composition and implications for particle viscosity
}

Wei Huang et al.

Correspondence to: Claudia Mohr (claudia.mohr@aces.su.se)

The copyright of individual parts of the supplement might differ from the CC BY 4.0 License. 
Table S1. Particle mass loadings $(\mu \mathrm{g})$ on the filter and corresponding sampling times $(\mathrm{min})$ at $\mathrm{t} 0$ and $\mathrm{t} 1$.

\begin{tabular}{lllll}
\hline \multirow{2}{*}{ Exp. name } & \multicolumn{2}{c}{$\mathrm{t} 0$} & $\mathrm{t} 1$ \\
\cline { 2 - 5 } & Mass loadings $(\mu \mathrm{g})$ & Sampling time $(\mathrm{min})$ & Mass loadings $(\mu \mathrm{g})$ & Sampling time $(\mathrm{min})$ \\
\hline WDtoCH & 4.07 & 20 & 3.93 & 20 \\
WHtoCH & 2.34 & 20 & 2.33 & 20 \\
$\mathrm{CH}$ & 6.60 & 13.5 & 6.19 & 5 \\
$\mathrm{CD}$ & 11.06 & 20 & 4.01 & 5 \\
\hline
\end{tabular}



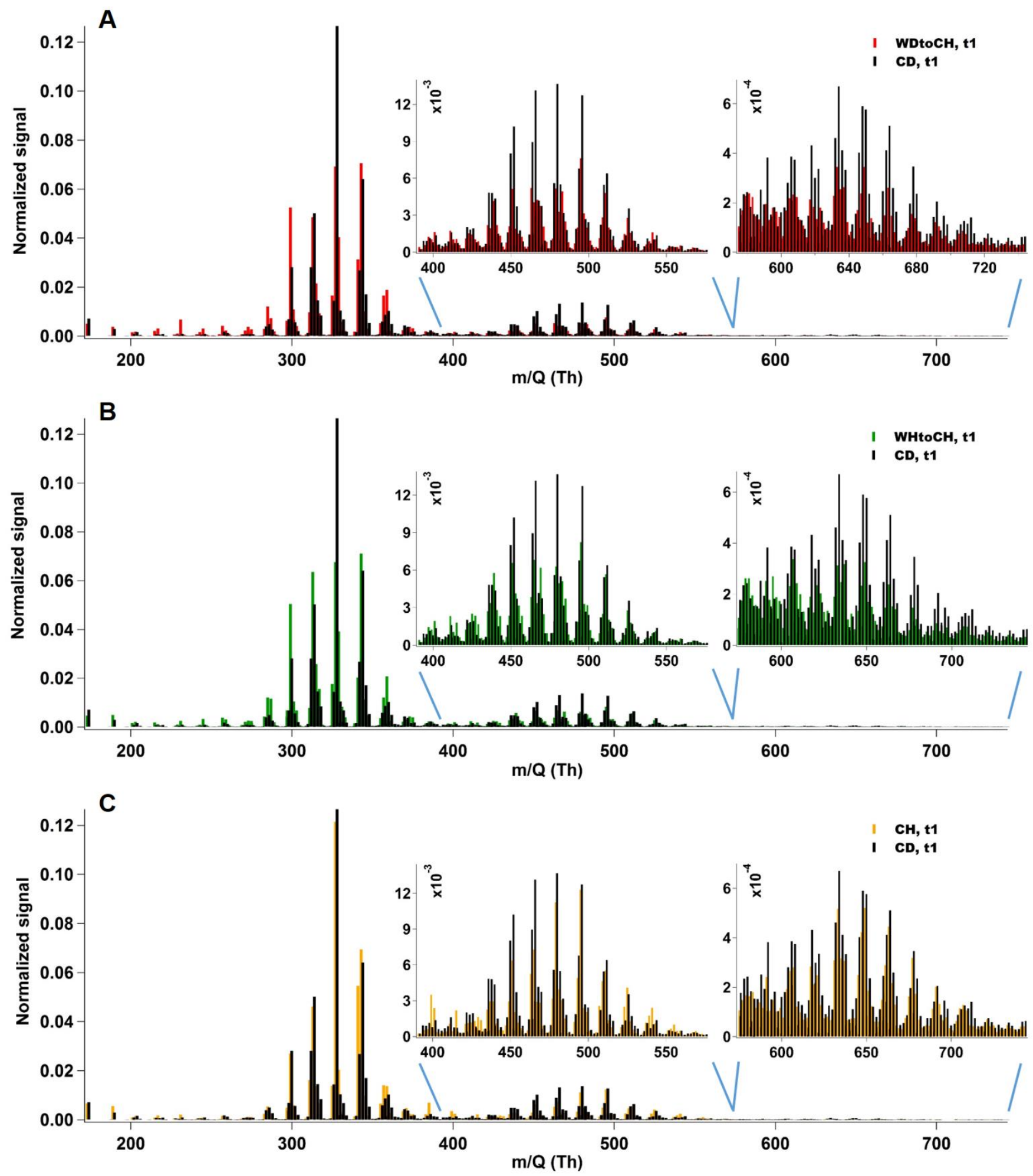

Figure S1. FIGAERO-CIMS mass spectra (normalized to the sum of signal of all detected CHOI compounds) of experiments WDtoCH and

$\mathrm{CD}(\mathrm{A}), \mathrm{WH}$ toCH and $\mathrm{CD}(\mathrm{B}), \mathrm{CH}$ and $\mathrm{CD}(\mathrm{C})$ at $\mathrm{t}$. Inserts show enlarged regions of dimers (left) and trimers (right). 


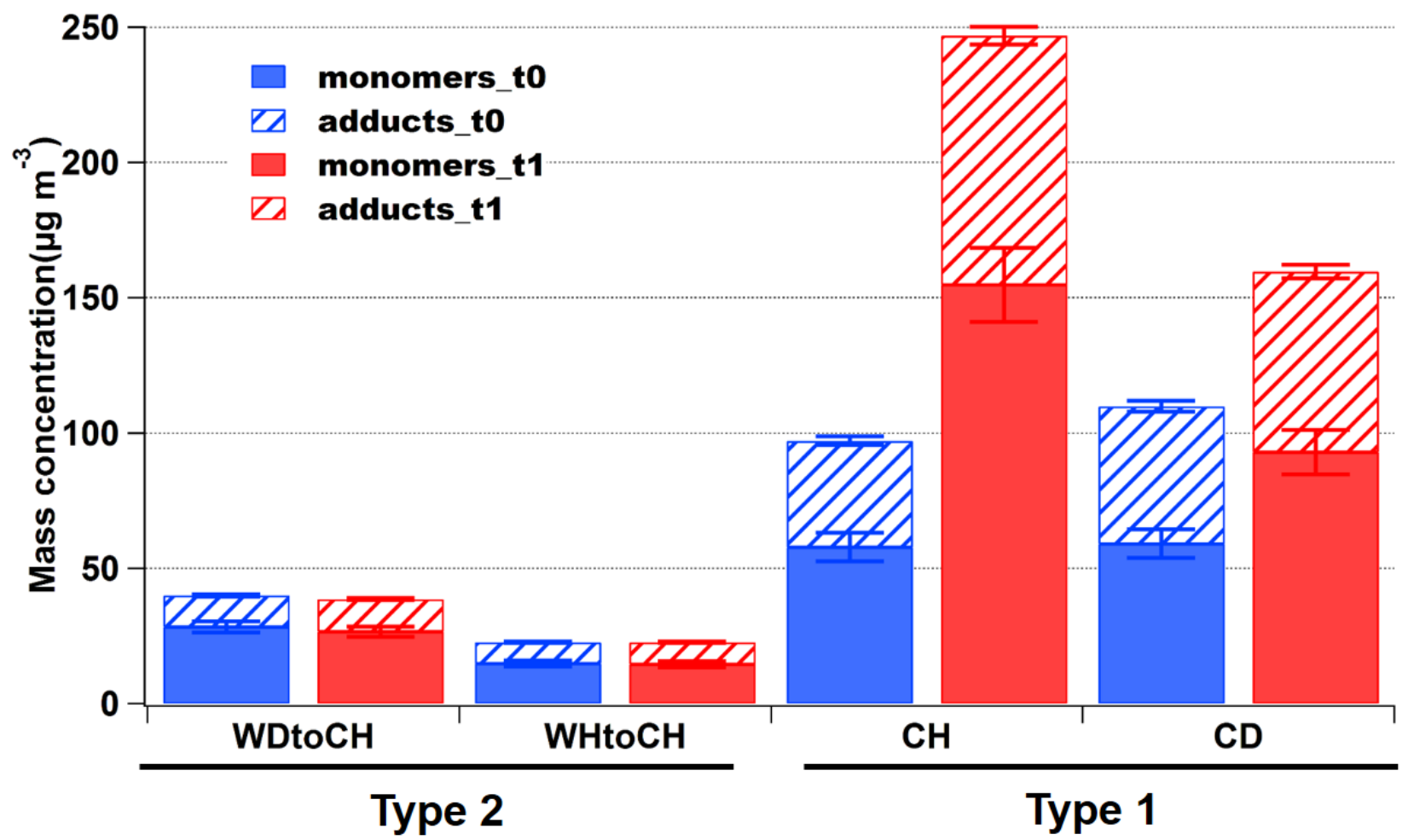

Figure S2. Absolute mass concentrations of monomers and adducts with error bars at t0 (blue) and t1 (red). 

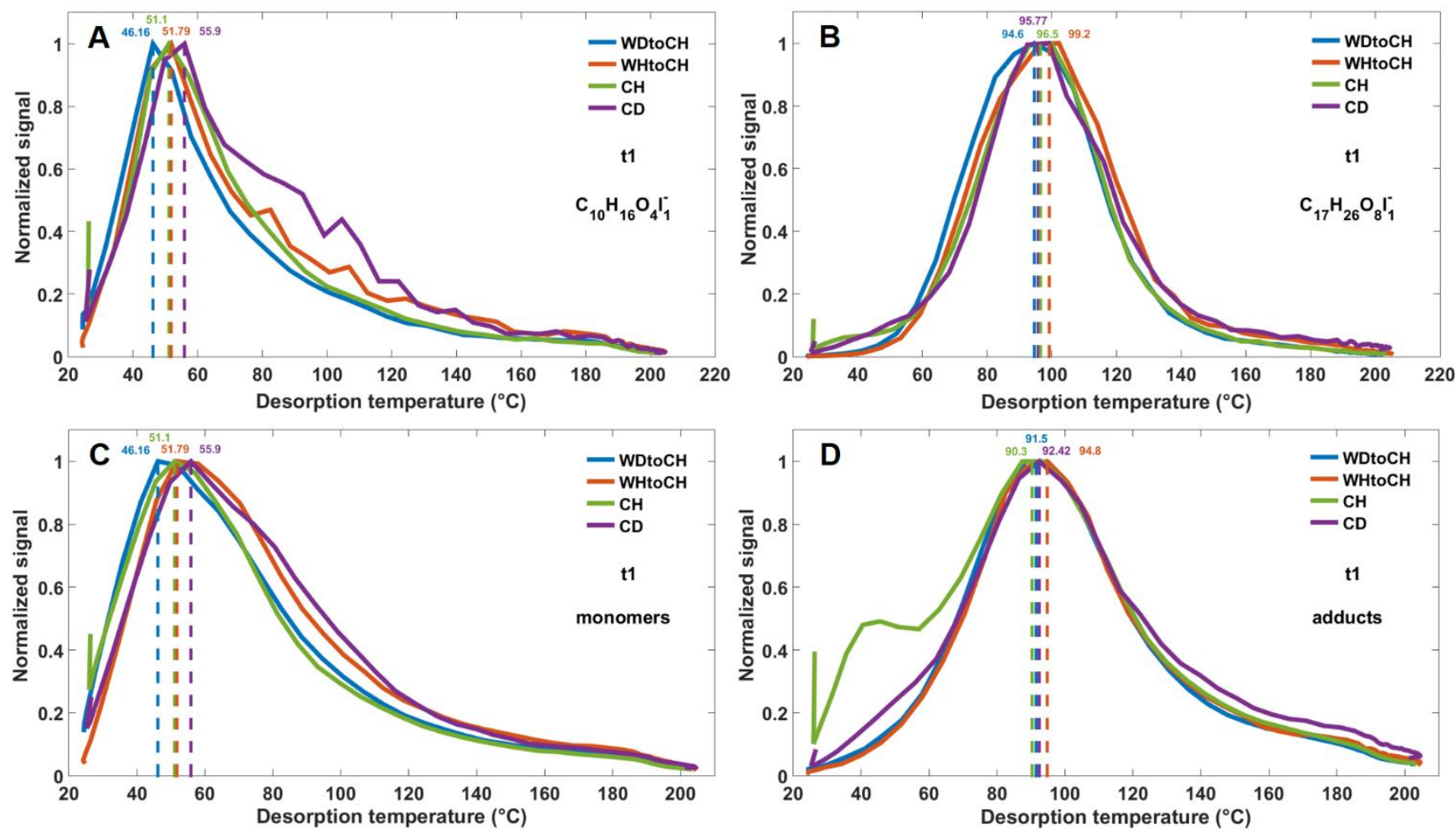

Figure S3. Thermograms of a monomer, $\mathrm{C}_{10} \mathrm{H}_{16} \mathrm{O}_{4}$ (A) and an adduct, $\mathrm{C}_{17} \mathrm{H}_{26} \mathrm{O}_{8}$ (B) both clustered with $\mathrm{I}^{-}$at t1; sum thermograms of monomers (C) and adducts (D) at $\mathrm{t} 1$. Dashed lines refer to the corresponding $\mathrm{T}_{\max }$. 

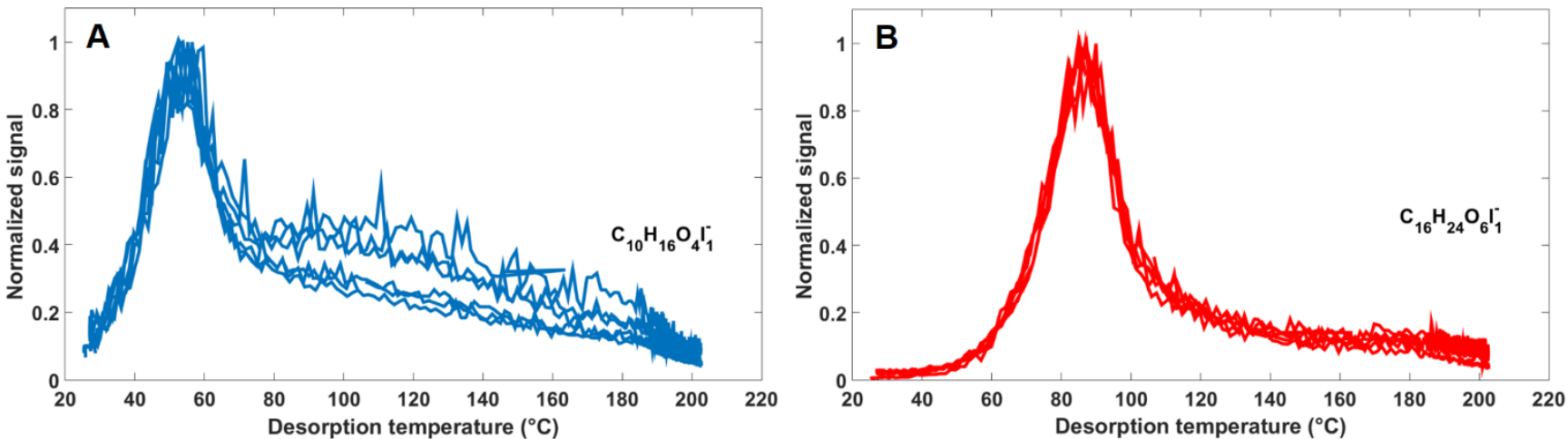

Figure S4. Thermograms of a monomer, $\mathrm{C}_{10} \mathrm{H}_{16} \mathrm{O}_{4}(\mathrm{~A})$ and an adduct, $\mathrm{C}_{16} \mathrm{H}_{24} \mathrm{O}_{6}$ (B) both clustered with $\mathrm{I}^{-}$under stable conditions. 

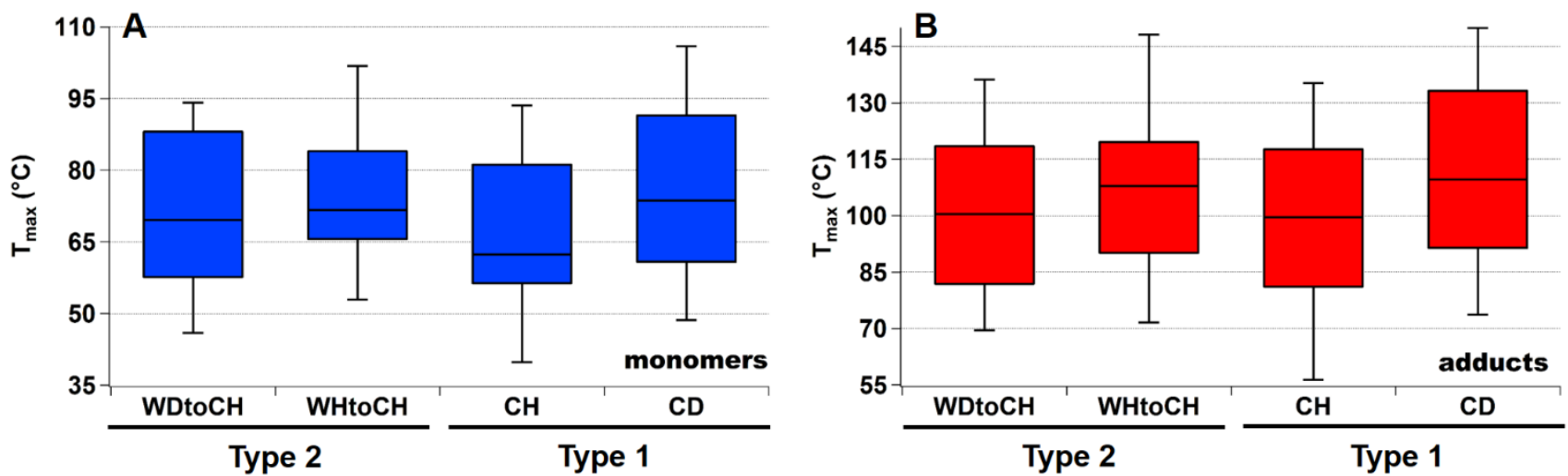

Figure S5. $\mathrm{T}_{\max }$ box plot for monomers (A) and adducts (B) for four experiments at t0. 
Different mass loadings on the filter due to different sampling times and/or sample concentrations influence thermogram shapes and thus $\mathrm{T}_{\max }$. Thermograms of the sums of all CHOI compounds, monomers and adducts for different filter mass loadings for $\mathrm{WHtoCH}$ and $\mathrm{CD}$ experiments were compared (Figure S6). The corresponding filter mass loadings are listed in Table S2. The box plot of $\mathrm{T}_{\max }$ of all CHOI compounds, monomers and adducts increased with increasing mass loading on the 20 filter (Figure S7). Beyond filter mass loadings of 2-4 $\mu$ g the curves levelled off (saturation effect). Potential reasons for the observed effect of filter mass loading on $\mathrm{T}_{\max }$ values are increased heat capacity of the increasing mass of the particle matrix, particle-particle interactions, and diffusion limitations due to several particle layers. 

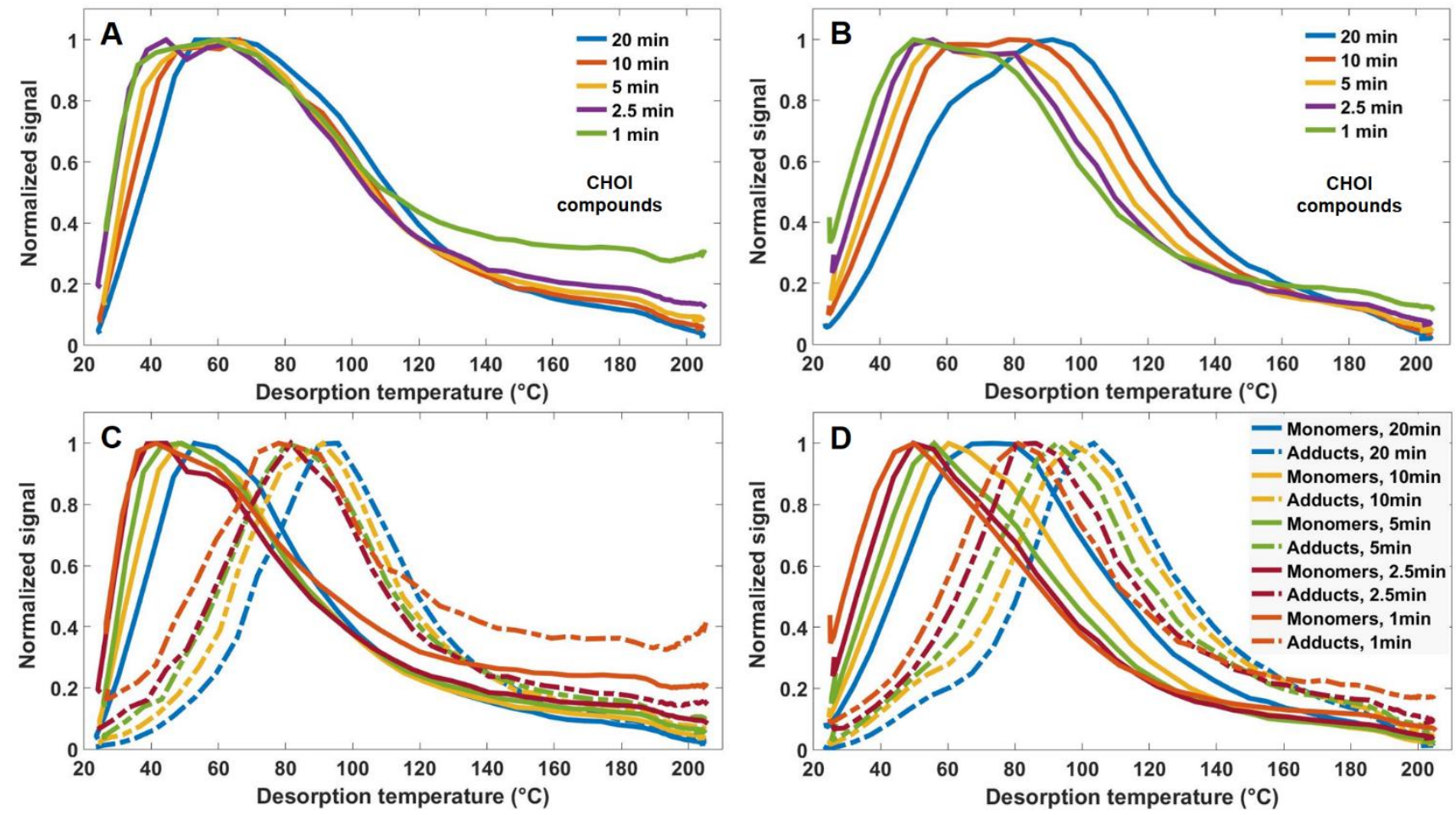

Figure S6. Sum thermograms of CHOI compounds with different sampling time for WHtoCH (A) and CD (B) experiments, and sum

thermograms of monomers (solid lines) and adducts (dashed lines) for WHtoCH (C) and CD (D) experiments. 
Table S2. Mass loadings ( $\mu \mathrm{g})$ on the filter with different sampling time for $\mathrm{WH}$ toCH and $\mathrm{CD}$ experiments.

\begin{tabular}{llllll}
\hline \multirow{2}{*}{ Exp. name } & \multicolumn{5}{c}{ Mass loadings $(\mu \mathrm{g})$} \\
\cline { 2 - 6 } & $20 \mathrm{~min}$ & $10 \mathrm{~min}$ & $5 \mathrm{~min}$ & $2.5 \mathrm{~min}$ & $1 \mathrm{~min}$ \\
\hline WHtoCH & 2.36 & 1.24 & 0.60 & 0.38 & 0.20 \\
CD & 11.06 & 7.25 & 4.01 & 2.08 & 0.94 \\
\hline
\end{tabular}



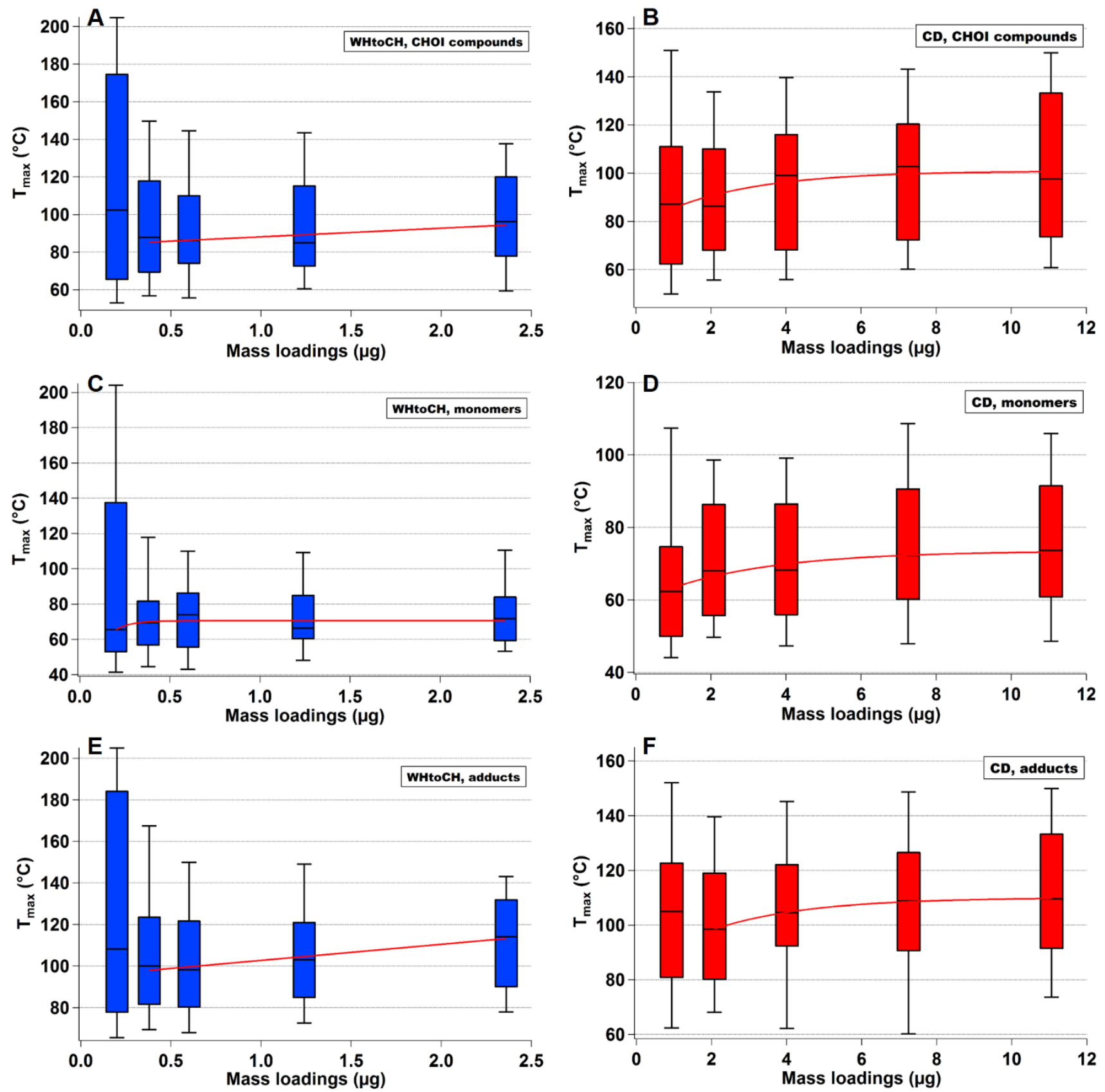

Figure S7. Box plot of $\mathrm{T}_{\max }$ at different mass loadings for $\mathrm{CHOI}$ compounds $(\mathrm{A}-\mathrm{B})$, monomers $(\mathrm{C}-\mathrm{D})$ and adducts $(\mathrm{E}-\mathrm{F})$ for $\mathrm{WHtoCH}$

(left) and CD (right) experiments. Red lines refer to the exponential curves fitted for the median $\mathrm{T}_{\max }$ in $(\mathrm{A}-\mathrm{D})$ and $(\mathrm{F})$ except for linear fit in $(\mathrm{E})$. 